\title{
RESEARCH
}

\section{ADAPTATION OF THE AGING SEMANTIC DIFFERENTIAL SCALE INTO TURKISH}

Turkish Journal of Geriatrics

DOI: 10.31086/tigeri.2021.222

2021; 24(2): 255-263

- Melike Eğer AYDOĞMUş1

CORRESPONDANCE

\section{${ }^{1}$ Melike Eğer AYDOĞMUŞ}

Hacettepe University, Psychology, ANKARA, Turkey

Phone: +903122978325

e-mail: melike.aydogmus@hacettepe.edu.tr

Received: Jan 14, 2021

Accepted: May 21, 2021

${ }^{1}$ Hacettepe University, Psychology, ANKARA, Turkey

\section{Abstract}

Background: The aim of this study was to adapt the Aging Semantic Differential Scale into Turkish. Rosencranz and McNevin (1969) first developed this scale to measure ageism and specific attitudes toward old people. Since then, this scale has been adapted into many languages, though not Turkish, and widely used in gerontology literature.

Method: This current study involved 204 volunteer Turkish undergraduate students registered at Hacettepe University (139 females, mean age 20.6). They completed the questionnaires in a test-retest format in their classrooms.

Results: Factor analyses revealed that the Turkish form had 26 items and 4 factors with an eigenvalue greater than 1 and explaining $46.8 \%$ of the total variance. The scale also highly correlated to two other scales on ageism, The Attitudes Toward Old People Scale and The Ageism Attitude Scale. Its internal reliability and two-week interval test-retest reliability scores were high.

Conclusion: In conclusion, the Turkish form of the Aging Semantic Differential Scale is a valid and reliable tool. By adapting a well-known ageism scale into Turkish, this study makes an important contribution to Turkish gerontology literature.

Keywords: Ageism; Semantic Differential 


\section{INTRODUCTION}

Ageism refers to negative attitudes toward an individual or group of people based on their biological age (1). These attitudes can emerge through thoughts, feelings, or actions as stereotypes, prejudice, or discrimination, respectively (2). Research shows that old people are more frequently exposed to these negative attitudes than young people (3).

Being subject to ageism harms individuals' physical and psychological wellbeing. The degree of these effects depends on several factors, such as age, the extent to which individuals associate these attitudes with themselves, and the life domains in which these attitudes are based (4). A recent study on old age ageism indicates that ageism negatively affects life satisfaction as people grow older (4). Specifically, elders who perceive old age positively report higher life satisfaction than their counterparts with negative perceptions of old age. However, this relationship is not significant among young people. Other studies reveal the long-term effects of ageism: for instance, two longitudinal studies demonstrate that internalized ageism negatively affects elders' cognitive performance and personality development over time $(5,6)$. While old people suffer from all of these aspects in their daily lives, ageism among healthcare workers also weakens the quality of healthcare elders receive. Therefore, ageism among healthcare professionals can worsen old people's health conditions (7). Overall, in addition to the physical and mental difficulties of old age, elders can also suffer from ageism.

Using both explicit and implicit measures, a considerable amount of literature has been published in the last few decades on the sources and consequences of ageism and possible precautions against it $(4,8,9)$. The level of ageism people show is affected not only by demographic factors (i.e., age, gender), but also the life domains in which age groups are evaluated. For instance, Kornadt and Rothermund (2011) asked approximately 700 volunteers to rate their attitudes toward old people based on eight life domains. In general, the participants rated old people positively in the "religion and spirituality" and "family and partnership" domains but negatively in "physical and mental fitness" and "financial situation." (4). However, these results varied depending on the participants' age: old people reported high levels of ageism for some domains (e.g., "religion and spirituality") while young people showed a similar tendency in different domains (e.g., "physical and mental fitness"). Another study by Kornadt et al. (2013) stressed the importance of both age and gender. According to this study, young people demonstrate ageism more than old people and target old males more than old females (10). Even though the researchers could not find a gender effect among young participants, the level of ageism fluctuated depending on the target's gender among old and middle-aged participants. In the same study, these relationships depended on the life domains in which elders were evaluated, in parallel to previous findings. While female elders were rated more negatively in the "work" and "finances" domains, male elders were rated more negatively in the "religion" and "friends" domains.

This study aimed to adapt a well-known ageism scale, the Aging Semantic Differential Scale (ASD) into Turkish. This scale asks participants from various age groups to report their attitudes toward old people. This scale was first developed by Rosencranz and McNevin (1969) as a semantic differential scale (11). Semantic differential scales are one form of forced-choice scales, which also include Likert scales, created by Osgood et al. in 1957 (12). While participants rate the degree of their agreement with a particular statement in Likert scales, in semantic differential scales, they rate their attitudes toward a situation or group of people based on a line scale between two opposite adjectives (13). To date, semantic differential scales have been widely used in various research areas from pain assessments (14) to self-concept evaluations (15). Research shows that these scales reveal statistically more valid results in 
measuring psychological constructs compared to Likert scales (16) however only a few Turkish studies utilize them (17).

To sum up, ageism negatively affects people's psychological and physical wellbeing, cognitive and personality development. In addition, old people are subject to ageism more than young people. The ASD, the most widely used ageism scale in gerontology literature, has been adapted into various languages $(3,18)$. For these reasons, this study can make an important contribution to Turkish gerontology literature and consequently to old people's wellbeing by adapting the ASD into Turkish.

\section{MATERIALS AND METHOD}

The academic ethics board at Hacettepe University approved this research. In total, 204 undergraduates registered at Hacettepe University participated in the study.

In this study we used three scales on ageism: The Aging Semantic Differential Scale (ASD), The Attitudes Toward Old People Scale, The Ageism Attitude Scale. Rosencranz and McNevin first developed the ASD in 1969, which asks participants to report their attitudes toward old people depending on line scales divided into seven degrees between 32 opposite adjective pairs as illustrated below:

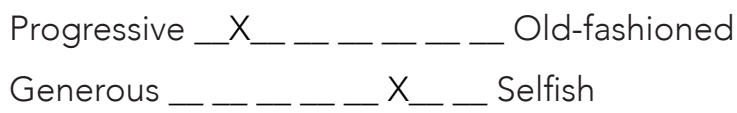

Participants can score between 32 and 224 on the scale, with higher scores denoting a more negative attitude toward old people. The original scale had three factors: instrumentality, autonomy, and acceptability. However, later studies that reassessed the ASD's psychometric properties support a four-factor model with the original three factors and the new addition of integrity $(3,19)$.

The Attitudes Toward Old People Scale was developed by Kogan in 1961 to measure ageism to- ward old people (20). It consists of 34 items, with 17 positive and 17 negative propositions rated on a 6-point Likert scale. The negative items are reverse-coded; therefore, high scores indicate more positive attitudes toward old people. In 2013, Duyan and Gelbal (21) adapted this scale into Turkish and note that the Turkish form has good reliability and validity scores.

The Ageism Attitude Scale was developed by Vefikulucay and Terzioglu to measure discrimination against old people in 2011 (22). Participants rate their agreement with 23 propositions on a 5-point Likert scale. The scale is composed of three factors: restrictions in elders' lives, negative ageism, and positive ageism. Participants can score between 23 and 115 on the scale. The first two factors are reverse-coded, meaning high scores represent less discrimination against old people. Vefikulucay and Terzioglu report that the scale has good psychometric properties (22)

The researcher and another academic who speaks both English and Turkish translated the ASD into Turkish via a back-translation technique. Afterwards, 15 graduate students with a mean age of 23 completed the scale for a pilot study. They reported that the items were easy to follow. The scale items in their original form and their Turkish translations are listed in Table 1.

The volunteers completed the demographics and three scales on ageism including the ASD in their classrooms via paper-pencil method. Two weeks later, all participants filled out the ASD again using the same method, to assess the test-retest validity.

We started psychometric analyses of the scale with factor analyses using the SPSS and the AMOS programs. After the analyses confirmed the structural validity of the scale, the SPSS program was used to run the remaining validity and reliability tests (i.e., convergent validity, internal reliability and test-retest reliability). 
Table 1. Overview of the items of the Original Version and the Turkish Version of the Aging Semantic Differential Scale (ASD).

\begin{tabular}{|l|l|}
\hline \multicolumn{1}{|c|}{$\begin{array}{c}\text { Original ASD } \\
\text { (Rosencrantz \& McNevin, }\end{array}$} & Turkish Translation of ASD \\
\hline 1. Progressive-Old-fashioned & Yenilikçi-Eski kafalı \\
2. Consistent-Inconsistent & Tutarlı-Tutarsız \\
3. Independent-Dependent & Bağımsız-Bağımlı \\
4. Rich-Poor & Zengin-Fakir \\
5. Generous-Selfish & Cömert-Bencil \\
6. Productive-Unproductive & Üretken-Üretken değil \\
7. Busy-Idle & Meşgul-Başıboş \\
8. Secure-Insecure & Güvenli-Güvenli değil \\
9. Strong-Weak & Güçlü-Zayıf \\
10. Healthy-Unhealthy & Sağlıklı-Sağlıksız \\
11. Active-Passive & Aktif-Pasif \\
12. Handsome-Ugly & Güzel-Çirkin \\
13. Cooperative-Uncooperative & İşbirlikçi-Işbirlikçi değil \\
14. Optimistic-Pessimistic & İyimser-Kötümser \\
15. Satisfied-Dissatisfied & Tatminkar-Tatminsiz \\
16. Expectant-Resigned & Beklentisi olan-Kabullenmiş \\
17. Flexible-Inflexible & Esnek-Katı \\
18. Hopeful-Dejected & Umutlu-Umutlu değil \\
19. Organized-Disorganized & Düzenli-Düzensiz \\
20. Happy-Sad & Mutlu-Üzgün \\
21. Friendly-Unfriendly & Canayakın-Soğuk \\
22. Neat-Untidy & Tertipli-Dağınık \\
23. Trustful-Suspicious & Güvenilir-Şüphe uyandıran \\
24. Self-reliant-Dependent & Özgüvenli-Başkalarına bağımlı \\
25. Liberal-Conservative & Özgürlükçü-Muhafazakar \\
26. Certain-Uncertain & Kendinden emin-Emin değil \\
27. Tolerant-Intolerant & Hoşgörülü-Hoşgörüsüz \\
28. Pleasant-Unpleasant & Hoş-Nahoş \\
29. Ordinary-Eccentric & Sıradan-Alsssılmamış \\
30. Aggressive-Defensive & Saldırgan-Savunucu \\
31. Exciting-Dull & Heyecan verici-Sıkıcı \\
32. Decisive-Indecisive & Kararlı-Kararsız \\
\hline
\end{tabular}

\section{RESULTS}

The sample consisted of 139 females and 65 males. Their mean age was 20.62 and $63 \%$ were majoring in social sciences.

An exploratory factor analysis (EFA) with varimax rotation helped determine the number of factors in the Turkish ASD form. At first, we checked whether the Kaiser Meyer Olkin (KMO) value was higher than .80 and if Bartlett's Test of Sphericity (BTS) was significant. The results showed that the KMO was .84 and BTS was significant $\left(\chi^{2}(496)=2698.71, p\right.$ $<.001)$, as expected (23). The EFA showed that a four-factor structure explained $46.8 \%$ of the total variance, with an eigenvalue greater than 1 . We removed 7 items that were not represented by these factors from the Turkish ASD. The factor loadings for each item are listed in Table 2.

A confirmatory factor analysis (CFA) through AMOS showed that this initial model did not fit the data $(\chi 2(318)=701.285, p=.00, C F I=.79$, RMSEA $=.07)$. Depending on the modification indices, we added covariances between error terms to the following items: items 8 and 23 in the acceptance domain; items 26 and 32 in the autonomy domain; items 2 and 32 in the autonomy domain; and items 10 and 11 in the instrumentality domain. In addition, item 15 was moved from the integrity domain to the acceptance domain depending on the modification indices. This change was acceptable for two reasons. First, as can be seen from Table 2, item 15 was represented in both dimensions with similar factor loadings (.50 vs. .46). Second, this adjective pair was represented in the acceptance dimension in previous studies (3). In the end, the final model showed a sufficient fit with the model $(\chi 2(265)=485.48, p=$ $.00, \mathrm{CFI}=.87$, RMSEA $=.06$ ). Figure 1 shows additional details of the final model.

Lastly, we tested whether previous versions of the ASD better fit the data. Unfortunately, neither the original version with 32 items and three factors $(\chi 2(461)=1424.792, p=.00, C F I=.59$, RMSEA $=$ .10) (11) nor the updated version of the scale with 25 items and four factors fit the data $(\chi 2(293)=819.88$, $\mathrm{p}=.00, \mathrm{CFI}=.69$, RMSEA $=.09)$, (3).

To test the Turkish ASD's convergent validity, Pearson correlations were conducted for it, the Ageism Attitude Scale, and the Attitudes Toward Old People Scale. As anticipated, the ASD negatively correlated with the total scores of the Ageism Attitude Scale $(r=-.58 ; p<.01)$ and the Atti- 
Table 2. Factor Loadings of the Items in the Turkish Form of the ASD.

\begin{tabular}{|c|c|c|c|c|}
\hline & Instrumentality & Autonomy & Integrity & Acceptance \\
\hline 1. Progressive-Old-fashioned & .55 & & & \\
\hline 3. Independent-Dependent & .50 & & & \\
\hline 6. Productive-Unproductive & .47 & & & \\
\hline 9. Strong-Weak & .40 & & & \\
\hline 10. Healthy-Unhealthy & .64 & & & \\
\hline 11. Active-Passive & .73 & & & \\
\hline 17. Flexible-Inflexible & .46 & & & \\
\hline 25. Liberal-Conservative & .67 & & & \\
\hline 31. Exciting-Dull & .49 & & & \\
\hline 2. Consistent-Inconsistent & & .55 & & \\
\hline 24. Self-reliant-Dependent & & .55 & & \\
\hline 26. Certain-Uncertain & & .69 & & \\
\hline 32. Decisive-Indecisive & & .70 & & \\
\hline 16. Expectant-Resigned & & & .74 & \\
\hline 18. Hopeful-Dejected & & & .81 & \\
\hline 20. Happy-Sad & & & .54 & \\
\hline 5. Generous-Selfish & & & & .55 \\
\hline 8. Secure-Insecure & & & & .62 \\
\hline 13. Cooperative-Uncooperative & & & & .46 \\
\hline 14. Optimistic-Pessimistic & & & & .55 \\
\hline 15. Satisfied-Dissatisfied & & & .50 & .46 \\
\hline 21. Friendly-Unfriendly & & & & .63 \\
\hline 23. Trustful-Suspicious & & & & .73 \\
\hline 27. Tolerant-Intolerant & & & & .62 \\
\hline 28. Pleasant-Unpleasant & & & & .46 \\
\hline
\end{tabular}


Figure1. Measurement Model Developed Depending on the Confirmatory Factor Analysis using AMOS.

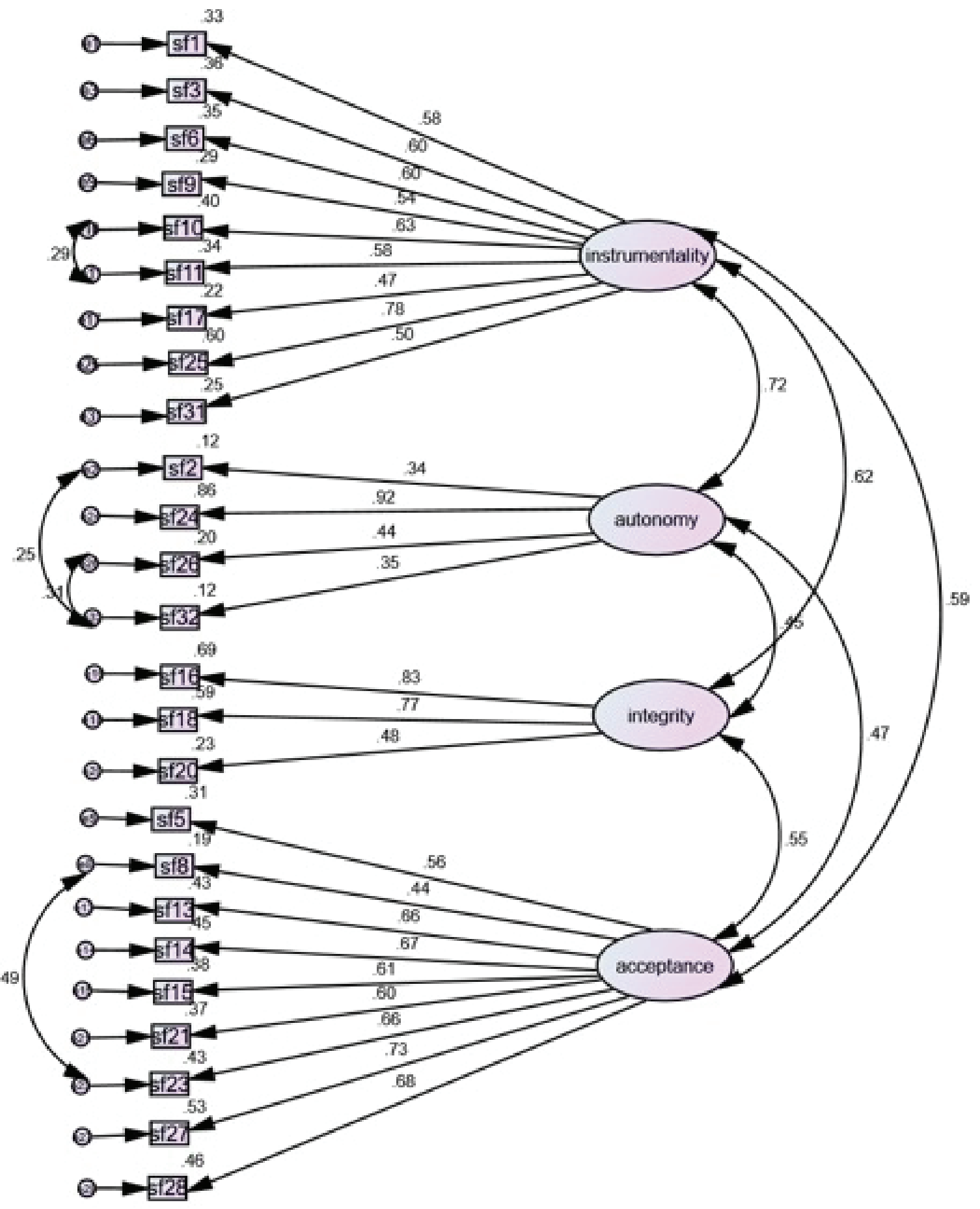


tudes Toward Old People Scale $(r=-.62 ; p<.01)$. In addition, the ASD significantly correlated with the sub-domains of these scales in the expected directions. The correlation coefficients are listed in Table 3. Except for the restrictions sub-domain of the Ageism Attitude Scale which revealed a low correlation, the adapted form of the ASD was found to be highly correlated with other scales on ageism in general.

For the one-factor model, confirmatory factor analysis yielded a high internal reliability $(\alpha=.90)$. The Cronbach's alpha value was .83 for the instrumentality domain, .72 for the integrity domain, .66 for the autonomy domain, and .85 for the acceptance domain. The item-total correlations ranged between .35 and .66 in all sub-domains therefore all sub-items were sufficiently distinct, and the Turkish ASD's internal reliability was high.

Lastly, a Pearson correlation analysis showed that the ASD's two applications at a two-week interval were significantly correlated with a high degree $(r=.67 ; p<.001, n=204)$.

\section{DISCUSSION}

In this study, we adapted the ASD, which measures attitudes toward old people, into Turkish. This scale was first developed by Rosencranz and McNevin in 1969 and has been adapted into many other languages since then for wider use in gerontology literature $(3,18,19)$. While the EFA revealed that the scale had 25 items represented by four factors, a CFA showed that the final model fits the data well. In terms of convergent validity, the 25-item ASD displayed high correlation with two other ageism scales in the expected direction. Further analyses showed that the scale's internal and test-retest reliability were high. In summary, the Turkish form of the ASD shows good psychometric characteristics.

The variety of measurement techniques provides researchers flexibility and makes it easier to reach more diverse and multiple groups. Similar to the development of visual analog scales for children and illiterate people, people with concentration problems can more easily complete semantic differential scales compared to Likert scales that may

Table 3. Bivariate Correlation Results Between the ASD and Other Ageism Scales.

\begin{tabular}{|l|c|c|}
\hline \multicolumn{1}{|c|}{ Ageism Scales } & Sub-Domains & Correlation with The ASD \\
\hline Ageism Attitude Scale & & $-.58^{\star *}$ \\
\hline & Restrictions & $.29^{\star \star}$ \\
\hline & Negative Ageism & $.43^{\star *}$ \\
\hline Attitudes Toward Old People Scale & Positive Ageism & $-.49^{\star *}$ \\
\hline & & $-.62^{\star *}$ \\
\hline
\end{tabular}

Numbers indicate correlation coefficients, ${ }^{\star \star} p>0.01$. 
have long propositions. Even though semantic differential scales are not prevalent in Turkish academic studies, they have several advantages compared to Likert scales (16). As such, the Turkish ASD will make an important contribution to Turkish gerontology literature.

Although ageism occurs almost everywhere, its frequency and characteristics can vary from one society to another $(1,24)$. For this reason, the contents of ageism scales used in different societies may also vary. In this study, the ASD's Turkish form was represented by four factors similar to the scale's adaptations into other languages. In addition, the ASD's model fit scores parallel the scores obtained by those scales $(3,25)$. Still, there were small differences between the Turkish and other forms of the ASD (e.g., item number). This situation may have arisen from the characteristics of the sample or as a cultural effect.

In this study, we recruited college students in Turkey which prevents us from generalizing our results to other groups. Therefore, these results should be

\section{REFERENCES}

1. Akdemir N, Çınar Fi, Görgülü Ü. Perception of Ageing and Ageism. Turkish Journal of Geriatrics 2007; 10(4): 215-222. (in Turkish).

2. Hagestad GO, Uhlenberg P. The social separation of old and young: A root of ageism. Journal of Social Issues 2005; 61(2): 343-360. (DOI: 10.1111/j.15404560.2005.00409.x).

3. Gluth S, Ebner NC, Schmiedek F. Attitudes toward younger and older adults: The German aging semantic differential. International Journal of Behavioral Development 2010; 34(2): 147-158. (DOI: 10.1177/0165025409350947).

4. Kornadt AE, Rothermund K. Contexts of aging: Assessing evaluative age stereotypes in different life domains. Journals of Gerontology Series B: Psychological Sciences and Social Sciences 2011; 66(5): 547-556. (PMID: 21571702). replicated on different age groups in different cultures. In addition, this scale mainly focuses on one aspect of ageism, specifically stereotypes (i.e., negative generalizations) about old people. Therefore, future studies on this area of research should also include scales on prejudice and discrimination aspect of ageism to comprehensively assess negative attitudes towards elders.

In conclusion, there are few studies using semantic differential scales in the Turkish literature despite their advantages over Likert scales. The ASD has a semantic differential format and it is the most widely used ageism scale in the gerontology literature. This study showed that the Turkish form has good psychometric properties. Because of these reasons, this scale will enrich Turkish gerontology literature. Since ageism has detrimental effects on old people's physical and psychological well-being, we hope that this important contribution in the literature will help us understand the antecedents and dynamics of ageism better and consequently improve elders' life standards.

5. Kornadt AE. Do age stereotypes as social role expectations for older adults influence personality development? Journal of Research in Personality 2016; 60: 51-55. (DOI: 10.1016/j.jrp.2015.11.005).

6. Levy BR, Zonderman AB, Slade MD, et al. Memory shaped by age stereotypes over time. Journals of Gerontology: Series B. 2012; 67(4): 432-436. (PMID: 22056832).

7. Özdemir Ö, Bilgili N. Ageism in Health Care. Gülhane Medical Journal 2014; 56(2): 128-131. (in Turkish). (DOI: 10.5455/gulhane.32088).

8. Hummert ML, Garstka TA, Shaner JL. Stereotyping of older adults: The role of target facial cues and perceiver characteristics. Psychology and Aging 1997; 12: 107-114. (PMID: 9100271).

9. Hummert ML, Gartska TA, O'Brien LT, et al. Using the implicit association test to measure age differences in implicit social cognitions. Psychology and Aging 2002; 17: 482-495. (PMID: 12243389). 
10. Kornadt AE, Voss P, Rothermund K. Multiple standards of aging: Gender-specific age stereotypes in different life domains. European Journal of Ageing 2013; 10(4): 335-344. (PMID: 28804307).

11. Rosencranz HA, McNevin TE. A factor analysis of attitudes toward the aged. The Gerontologist 1969. (PMID: 5769675)

12. Osgood CE, Suci, GJ \& Tannenbaum PH. The Measurement of Meaning (No. 47). 1st edition. University of Illinois press, USA 1967

13. Joseph FR, Marina P, Rolph EA, et al. The Role of Response Formats on Extreme Response Style: A Case of Likert-Type vs. Semantic Differential Scales. Measurement and Research Methods in International Marketing 2011: 53-71. (DOI: 10.1108/S14747979(2011)0000022006).

14. Olaogun MO, Adedoyin RA, Ikem IC, et al. Reliability of Rating Low Back Pain with a Visual Analogue Scale and a Semantic Differential Scale. Physiotherapy Theory and Practice. 2004; 20(2): 135-142. (DOI: 10.1080/09593980490453048).

15. Reynolds F. Exploring Self-Image During Hot Flushes Using a Semantic Differential Scale: Associations Between Poor Self-Image, Depression, Flush Frequency and Flush Distress. Maturitas 2002, 42(3): 201-207. (PMID: 12161044).

16. Friborg $\mathrm{O}$, Martinussen $\mathrm{M}$, Rosenvinge JH. LikertBased vs. Semantic Differential-Based Scorings of Positive Psychological Constructs: A Psychometric Comparison of Two Versions of a Scale Measuring Resilience. Personality and Individual Differences 2006; 40(5): 873-884. (DOI: 10.1016/j.paid.2005.08.015).

17. Eker D. Attitudes of Turkish and American Clinicians and Turkish psychology Students Toward Mental
Patients. International Journal of Social Psychiatry 1985; 31(3): 223-229. (PMID: 4044157).

18. Gonzales E, Marchiondo LA, Tan J, et al. The Aging Semantic Differential in Mandarin Chinese: Measuring Attitudes Toward Older Adults in China. Journal of Gerontological Social Work 2017; 60(3): 245-254. (PMID: 28358235).

19. Holtzman JM, Beck JD, Kerber PE. Dimensional Aspects of Attitudes Toward the Aged. The Gerontologist 1979;19(5 Part II): 91.

20. Kogan N. Attitudes Toward Old People: The Development of a Scale and an Examination of Correlates. The Journal of Abnormal and Social Psychology 1961; 62(1): 44. (PMID: 13757539).

21. Duyan V, Gelbal S. The Adaptation of Attitudes Towards the Elderly Scale to Turkish with a Group of University Students. Turkish Journal of Geriatrics 2013; 16(2): 202-209. (in Turkish).

22. Vefikuluçay YD, Terzioglu F. Development and Psychometric Evaluation of Ageism Attitude Scale Among The University Students. Turkish Journal of Geriatrics 2011; 14(3): 259-268.

23. Çokluk Ö, Şekercioğlu G, Büyüköztürk Ş. Application of SPSS and LISREL for Multivariate Statistics. 1st edition. Pegem Academy, Ankara, Turkey 2010. (in Turkish).

24. Palmore EB. Research Note: Ageism in Canada and the United States. Journal of Cross-Cultural Gerontology 2004; 19(1): 41-46. (PMID: 15032226).

25. Intrieri RC, von Eye A, Kelly JA. The Aging Semantic Differential: A confirmatory factor analysis. The Gerontologist 1995; 35: 616-621. (PMID: 8543218). 